\title{
VOLUNTARY TAX COMPLIANCE UMKM KOTA DEPOK
}

\author{
Ai Annisaa Utami ${ }^{1)}$, Zahrudin $^{2)}$ \\ ${ }^{1,2}$ Program Studi Pendidikan Ekonomi, FIPPS \\ Universitas Indraprasata PGRI \\ Email: aiannisaa87@gmail.com
}

\begin{abstract}
Micro, small, and medium enterprises (SMEs) is an economic sector that has a significant role in national economies. Based on data from the Gross Domestic Product (GDP) in 2011, SMEs have accounted for approximately 57\% of total GDP. However, when compared with the contribution of SMEs to tax revenues, there is a miss-match in which the contribution of SMEs on the tax revenue is very small, ie less than $0.5 \%$ of total tax revenue.. The study aims to reveal the tax voluntary complaints made by the SMEs in the City Depok, methods of research using a survey of a number of SMEs contained in Depok. The sampling technique used in this research is purposive sampling with a sample of 30 SMEs to Bekasi and Depok. Outcomes of this research is a campaign booklet containing implementation guidelines and technical instructions complain voluntary tax that could be used by the SMEs in Depok City, and other outcomes are scientific publications National level
\end{abstract}

Keywords: SMEs, Voluntary Tax Compliance, Regulation 46 Year 2013

\begin{abstract}
ABSTRAK
Usaha mikro, kecil, dan menengah (UMKM) adalah merupakan sektor ekonomi yang mempunyai peran cukup besar dalam perekenomian nasional. Berdasarkan data Produksi Domestik Bruto (PDB) tahun 2011, UMKM mempunyai kontribusi kurang lebih 57\% total PDB. Namun demikian apabila dibandingkan dengan kontribusi UMKM terhadap penerimaan pajak, terdapat miss-match dimana kontribusi UMKM pada penerimaan perpajakan sangat kecil, yaitu kurang lebih $0.5 \%$ dari total penerimaan pajak.. Penelitian bertujuan untuk mengungkap voluntary tax complain yang dilakukan oleh para pelaku UMKM di Kota Depok, metode penelitian menggunakan survey terhadap sejumlah UMKM yang terdapat di Kota Depok. Teknik sampling yang digunakan dalam penelitian ini adalah purposive sampling dengan jumlah sampel 30 UMKM untuk wilayah Bekasi dan Depok. Hasil luaran penelitian ini adalah booklet kampanye yang berisi petunjuk pelaksanaan dan petunjuk teknis voluntary tax complain yang bisa digunakan oleh para pelaku UMKM di Kota Depok, dan luaran lainnya adalah publikasi ilmiah tingkat Nasional
\end{abstract}

Kata Kunci : UMKM, Voluntary Tax Compliance, PP 46 Tahun 2013 


\section{PENDAHULUAN}

Peran UMKM dalam perekonomian domestik semakin meningkat terutama setelah krsisis tahun 1997. Di saat perbankan menghadapi kesulitan untuk mencari debitur yang tidak bermasalah, UMKM menjadi alternatif penyaluran kredit perbankan. Berdasarkan data BPS tahun 2003 terdapat 42,39 jt UMKM atau 99,9 \% total unit usaha dan mampu menyerap tenaga kerja $79,4 \mathrm{jt}$ atau 99,4\% angkatan kerja Data BPS juga memperkirakan $57 \%$ PDB bersumber dari unit usaha ini dan menyumbang hampir $15 \%$ dari ekspor barang Indonesia . Ditinjau dari reputasi kreditnya, UMKM juga mempunyai prestasi yang cukup membanggakan dengan tingkat UMKM, Pemerintah telah menerbitkan Peraturan Pemerintah Nomor 46 Tahun 2013 tentang Pajak Penghasilan atas Penghasilan dari Usaha yang Diterima atau Diperoleh Wajib Pajak yang Memiliki Peredaran Bruto Tertentu (PP 46/2013). Dalam Peraturan Pemerintah ini diatur pengenaan Pajak Penghasilan ( $\mathrm{PPh}$ ) yang bersifat final atas penghasilan yang diterima atau diperoleh Wajib Pajak dengan batasan peredaran bruto tertentu.

Beberapa temuan di lapangan menunjukkan bahwa tingkat ketaatan UMKM untuk membayar pajak masih sangat rendah. Hal ini berdasarkan sebaran profit margin. Berdasar data profit margin UMKM, terdapat perbedaan sebaran profit margin usaha menengah dengan usaha kecil dan mikro. Pada usaha menengah, kemacetan kredit yang relatif kecil. Pada akhir tahun 2002 tingkat kredit bermasalah UMKM hanya mencapai $3,9 \%$ dibandingkan dengan total kredit perbankan yang mencapai $10,2 \%$.

Usaha Mikro Kecil dan Menengah (UMKM) saat mulai berkembang dengan baik dan mampu menghasilkan keuntungan. Oleh karena itu sudah selayaknya jika UMKM berpartisipasi dalam menambah penerimaan negara diantaranya melalui pembayaran pajak penghasilan. Berkaitan dengan perpajakan, maka Usaha Mikro Kecil dan Menengah sebagai wajib pajak harus memenuhi kewajiban di bidang perpajakan. Dalam upaya untuk mendorong pemenuhan kewajiban perpajakan secara sukarela (voluntary tax compliance) serta mendorong kontribusi penerimaan negara dari

mayoritas dari populasi, yaitu sebesar $64,5 \%$, memiliki profit margin kurang dari $10 \%$. Sisanya, sebesar $26 \%$ dari populasi memiliki profit margin antara $10 \%$ s.d. $50 \%$, dan hanya 9,5\% dari populasi yang memiliki profit margin di atas $50 \%$. Sementara itu, untuk usaha mikro dan kecil mayoritas dari populasi, yaitu 53,3\% untuk usaha mikro dan $49,8 \%$ untuk usaha kecil, memiliki profit margin antara $10 \%$ sampai dengan $50 \%$. Sementara itu profil yang memiliki profit margin di atas $50 \%$ sebanyak $35,1 \%$ untuk usaha mikro $34,9 \%$ untuk usaha kecil. Sisanya hanya sebanyak $15,3 \%$ usaha kecil dan $11,6 \%$ usaha mikro yang memiliki profit margin di bawah $10 \%$.

Gambar 1.1

Sebaran Profit Margin UMKM

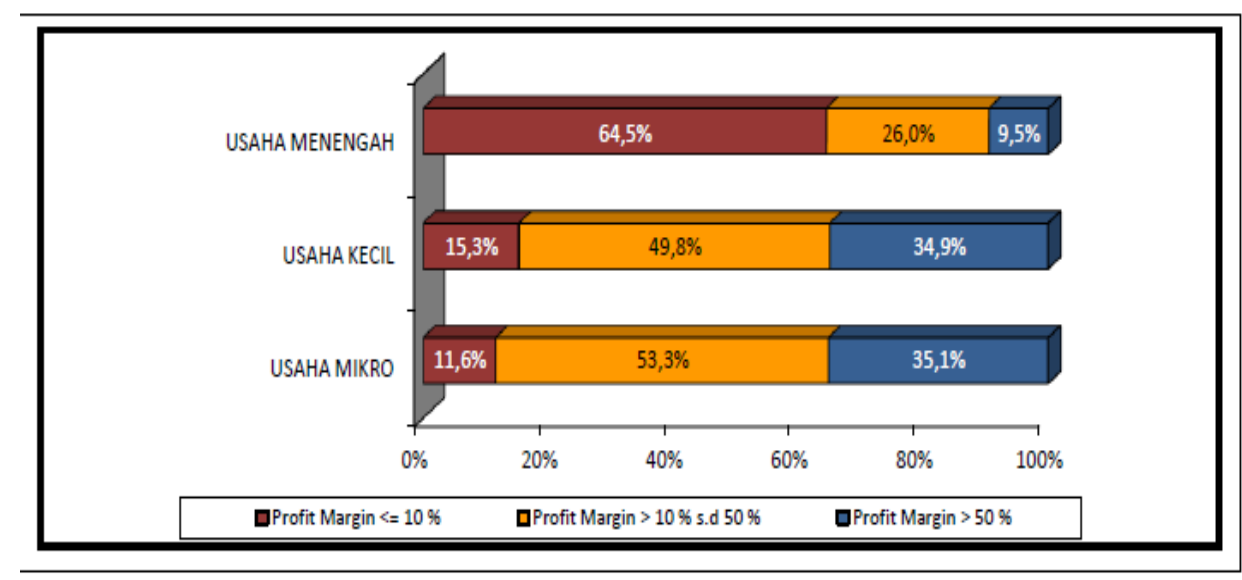

Sumber : Bank Indonesia 
Berdasarkan informasi diatas, sehingga penerapan single tarif (tanpa melihat sektoral) adalah dimungkinkan dapat dilaksanakan, namun faktanya serapan jumlah pajak dari sector UMKM belum mencapai target yang Berikut ini adalah paparan data jumlah UMKM aktif di Kota Depok tahun 2012 berdasarkan klasifikasi jenis usaha. telah ditetapkan oleh pemerintah (Suhairi, 2004), Perkembangan UMKM semakin meningkat tidak terkecuali untuk daerah Kota Depok.

Gambar 1.2

Kontribusi PDRB UMKM Kota Depok

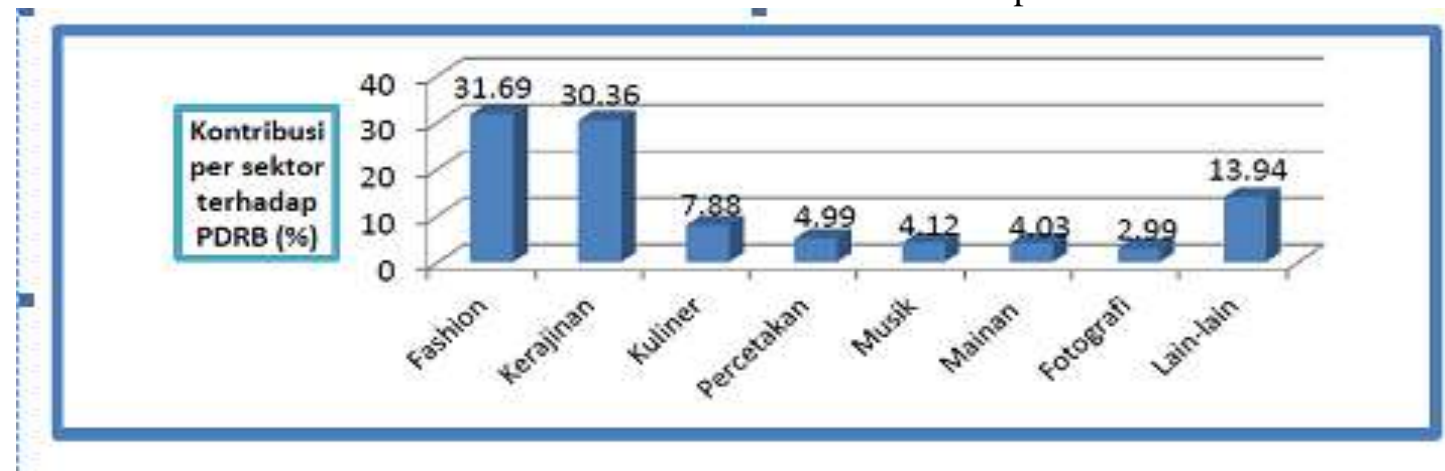

Penelitian ini merupakan upaya untuk membantu pemerintah dalam mensukseskan program UMKM taat dalam membayar pajak. Efek domino dari voluntary tax compliance UMKM memberikan kontribusi yang sangat besar untuk penerimaan Negara. Hasil luaran dari penelitian ini berupa booklet kampanye petunjuk pelaksanaan dan petunjuk teknis dalam menghitung pajak final yang harus dikeluarkan oleh UMKM sesuai dengan PP no 46 tahun 2013.

\section{Kriteria UMKM}

Satyo, (12: 2005) mengungkapkan bahwa UMKM dapat dikategorikan menjadi tiga terutama berdasar jumlah aset dan omzet sebagaimana tercantum di Undang - Undang Nomor 20 Tahun 2008 tentang UMKM sebagai berikut:

1. Usaha Mikro : Usaha produktif milik perseorangan dan atau badan usaha perseorangan yang memenuhi kriteria sebagai berikut :

- Aset $\leq$ Rp50.000.000,00 Memiliki kekayaan bersih kurang dari atau sama dengan Rp50.000.000,00 (lima puluh juta rupiah)

- Omzet $\leq$ Rp300.000.000,00 Memiliki hasil penjualan tahunan kurang dari Rp300.000.000,00 (tiga ratus juta rupiah)
2. Usaha Kecil : Usaha ekonomi produktif yang berdiri sendiri, yang dilakukan oleh orang perorangan atau badan usaha yang bukan merupakan anak perusahaan atau bukan cabang perusahaan yang dimiliki, dikuasai, atau menjadi bagian baik langsung maupun tidak langsung dari usaha menengah atau usaha besar yang memenuhi kriteria sebagai berikut :

- Rp50.000.000,00 < Aset $\leq$ Rp500.000.000,00 Memiliki kekayaan bersih lebih dari Rp50.000.000,00 (lima puluh juta rupiah) sampai dengan paling banyak Rp500.000.000,00 (lima ratus juta rupiah) tidak termasuk tanah dan bangunan tempat usaha); atau

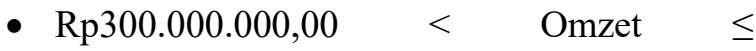
2.500.000.000,00 Memiliki hasil penjualan tahunan lebih dari Rp300.000.000,00 (tiga ratus juta rupiah) sampai dengan paling banyak Rp2.500.000.000,00 (dua milyar lima ratus juta rupiah).

3. Usaha Menengah: Usaha ekonomi produktif yang berdiri sendiri, yang dilakukan oleh perseorangan atau badan usaha yang bukan merupakan anak perusahaan atau cabang perusahaan yang dimiliki, dikuasai, atau menjadi bagian baik langsung maupun tidak langsung dengan usaha kecil atau usaha besar yang memenuhi kriteria sebagai berikut: 
- Rp500.000.000,-<Aset $\leq$ Rp10.000.000.000,Memiliki kekayaan bersih lebih dari Rp500.000.000,00 (lima ratus juta rupiah) sampai dengan paling banyak Rp10.000.000.000,- (sepuluh milyar rupiah)

- Rp2.500.000.000,-<0mzet $\leq$

Rp50.000.000.000,- Memiliki hasil penjualan tahunan lebih dari Rp2.500.000.000,00 (dua milyar lima ratus juta rupiah) sampai dengan paling banyak Rp50.000.000.000,00 (lima puluh milyar rupiah).

\section{Pajak}

Gunadi (20:2007) menyatakan, pajak merupakan salah satu instrumen penting yang digunakan pemerintah untuk menanggulangi pengeluaran. Pemerintah mengatur segala ketentuan dan aturan perpajakan di dalam peraturan perundang-undangan perpajakan, agar pembiayaan negara dapat terus berjalan lancar dengan mengandalkan iuran semaksimal mungkin dari masyarakat. Hal ini berkaitan dengan fungsi budgetair dari perpajakan itu sendiri. Penarikan atau pemungutan pajak adalah suatu fungsi yang harus dilaksanakan oleh negara sebagai suatu fungsi esensial. Tanpa pemungutan pajak sudah dapat dipastikan bahwa keuangan negara akan lumpuh terutama bagi negara yang sedang berkembang seperti Indonesia, karena pajak merupakan sumber pendapatan terbesar negara.

\section{Model Perpajakan UMKM}

Secara umum, model perpajakan UMKM dapat dibagi dalam dua kelompok besar, sebagaimana ditunjukkan pada gambar II.1. Kelompok pertama adalah sistem standard regime dan kedua sistem presumptive regime Benjamin, W.P (23:1990). Dalam standard regime, UMKM tidak dibedakan perlakuan perpajakannya. Namun demikian terdapat beberapa negara yang menerapkan standard regime dengan penyederhanaan formulir perpajakan, tata cara pembayaran, atau dengan pengurangan tarif (Williams, L.K., Chen, R.C., \& Tearney, M.G., 1989). Negara-negara yang menerapkan standard regime untuk UMKM pada umumnya adalah negara-negara maju, yang komunitas UMKM nya telah memiliki efisiensi administrasi tinggi dan mempunyai kemampuan book-keeping yang memadai (Wishon, K, 1985)

Gambar 1.3

Model Perpajakan UMKM

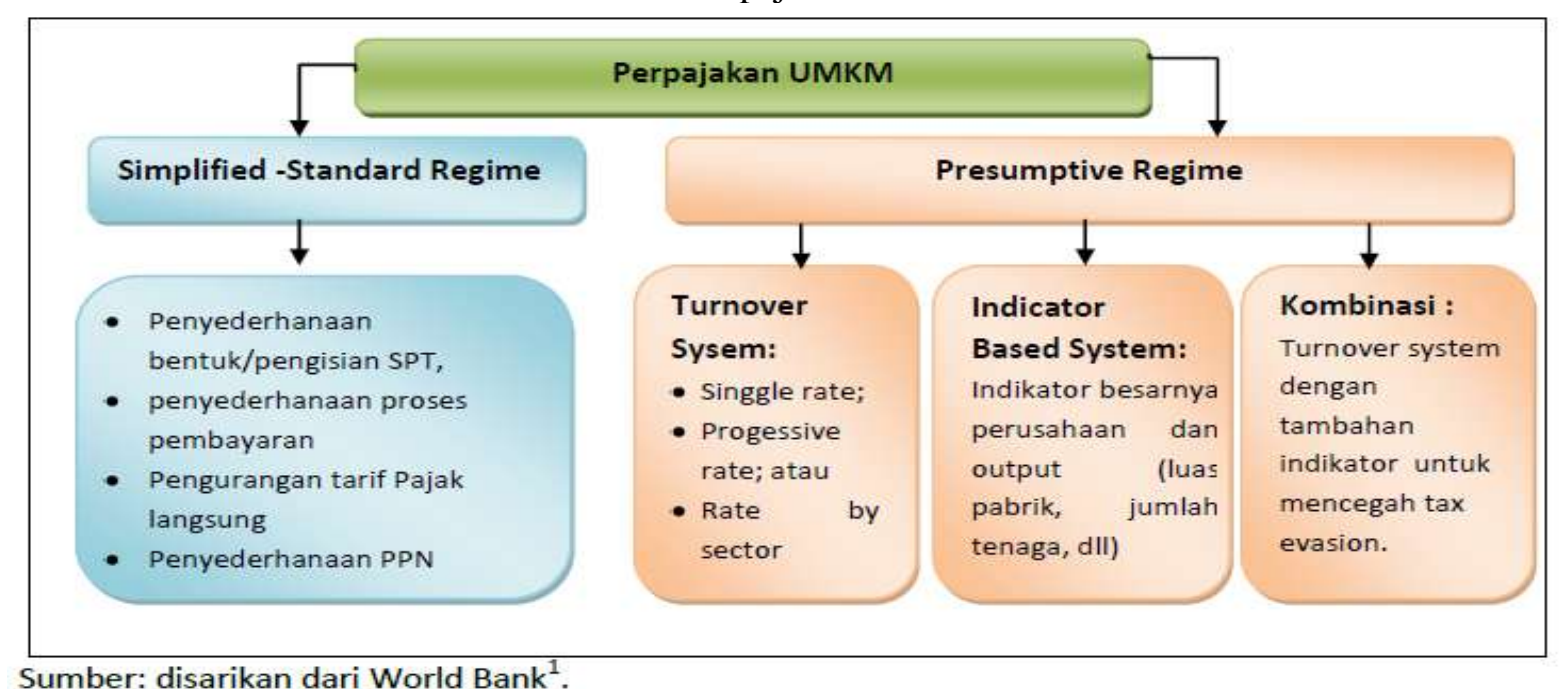

Sementara itu, dalam model presumptive regime, $\mathrm{PPh}$ dikenakan berdasarkan pada presumsi kondisi tertentu dari Wajib Pajak. Presumtive regime biasa digunakan terutama di negara di mana mayoritas pembayar pajaknya adalah kelompok yang susah untuk dipajaki ("hard to tax"), dan sumber daya adminstrasinya yang tidak memadai. Di negara tersebut sebagian besar wajib pajaknya tidak memiliki transparansi keuangan yang memungkinkan untuk pengenaan pajak secara efektif oleh pemerintah. Oleh karenanya, pemerintah perlu membuat perkiraan atau presumsi atas batasan pendapatan yang tepat 
untuk dikenai pajak. Presumptive regime lebih banyak diterapkan di negara-negara non-OECD. Regime ini pada umumnya digunakan dengan tujuan untuk meningkatkan compliance dan mendorong record keeping Wajib Pajak. Penerapan presumptive regime pada umumnya menggunakan turnover based system, indicator based system, atau gabungan keduanya. Namun demikian di negara transisi, turnover system merupakan model yang umum digunakan (Engelschak, M. \& Loeprick,J , 2009).

Sebelum berlakunya PP 46 Tahun 2013, Indonesia menerapkan model standard regime dengan kemudahan dan fasilitas tertentu (standard regime-simplified/reduced rate) (Suhairi dan Wahdini :2006). Kemudahan diberikan kepada Wajib Pajak Orang Pribadi (WP OP), sebagaimana di atur dalam Pasal 14 ayat (2) UU PPh, yaitu WP OP yang melakukan kegiatan usaha atau pekerjaan bebas yang peredaran brutonya dalam satu tahun kurang dari Rp4,8 miliar, diperkenankan untuk menggunakan Norma Penghitungan Penghasilan Neto (NPPN) dalam penghitungan penghasilan kena pajak nya. Sedangkan reduced rate diberlakukan untuk Wajib Pajak Badan, sebagaimana diatur dalam Pasal 31E UU PPh, bahwa WP Badan dalam negeri dengan peredaran bruto satu tahun sampai dengan Rp50 miliar, mendapat fasilitas berupa pengurangan tarif sebesar 50\% dari tarif normal $\mathrm{PPh}$ yang dikenakan atas Penghasilan Kena Pajak dari bagian peredaran bruto sampai dengan $\mathrm{Rp} 4,8$ miliar.

\section{METODE}

Jenis penelitian yang dilakukan oleh penulis adalah penelitian survey.Teknik analisis yang digunakan adalah analisis kualitatif dengan tipe deskriptif. Tipe penelitian deskriptif bertugas untuk melakukan representasi obyektif mengenai gejala-gejala yang terdapat di dalam masalah penelitian. Representasi itu dilakukan dengan mendeskripsikan gejala-gejala sebagai data atau fakta sebagaimana adanya (Richardson, Frederick M., Wright :1986

Langkah-langkah analisis yang dilakukan adalah:

1. Mengklasifikasikan data berdasarkan pelaporan pajak terhutang untuk masingmasing UMKM, yang diperoleh melalui wawancara semi terstruktur dan kuesioner.
2. Mengidentifikasikan factor-faktor yang menyebabkan voluntary tax compliance UMKM berjalan baik

3. Menganalisis kendala-kendala yang dihadapi UMKM dalam penerapan voluntary tax compliance PP No 46 tahun 2013.

4. Mengolah data dan membuat kesimpulan secara menyeluruh berdasarkan data yang diperoleh.

\section{HASIL DAN PEMBAHASAN}

Dalam Nota Keuangan dan Anggaran Pendapatan dan Belanja Negara Tahun Anggaran 2014, pendapatan dalam negeri meningkat rata-rata 8,0 persen dalam periode 2008-2012, didukung oleh pertumbuhan ratarata penerimaan perpajakan sebesar 10,5 persen dan PNBP (Penerimaan Negara Bukan Pajak) sebesar 2,3 persen. Penerimaan perpajakan dalam APBNP 2013 ditargetkan mencapai Rp.1.148,4 triliun, naik 17,1 persen dari realisasinya dalam tahun 2012. Perkembangan penerimaan perpajakan tahun 2008-2013 disajikan dalam gambar berikut ini.

\section{Gambar 1.4}

Perkembangan Penerimaan Perpajakan 20082014

Penerimaan perpajakan dalam RAPBN 2014 diperkirakan mencapai Rp.1.310,2 triliun,

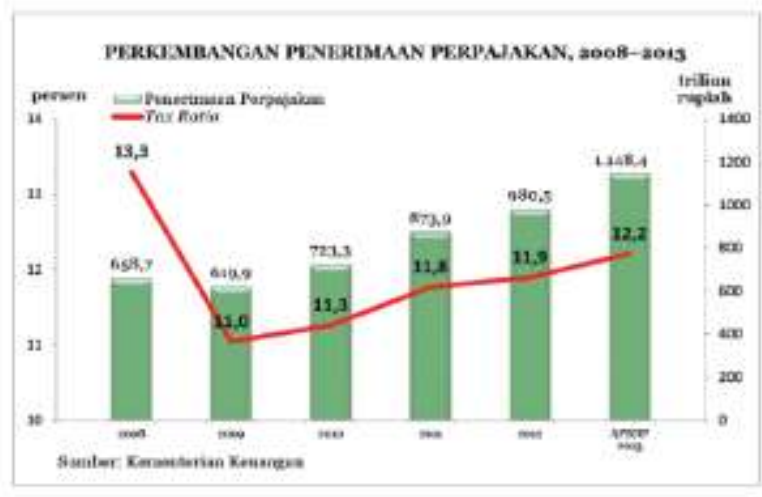

Sumber: Nota Kevangan dan APBN 2014

atau mengalami peningkatan sebesar Rp.161,9 triliun atau 14,1 persen bila dibandingkan dengan targetnya dalan APBNP 2013 (Nota Keuangan dan Anggaran Pendapatan dan Belanja Negara Tahun Anggaran 2014). Terkait upaya pencapaian target penerimaan perpajakan yang terus meningkat, pemerintah telah menerapkan beberapa kebijakan. Untuk saat ini pemerintah akan lebih memprioritaskan 
kebijakan untuk perluasan basis pajak, mengingat masih besarnya potensi yang ada dalam perekonomian, seperti sektor usaha mikro, kecil dan menengah (UMKM).

Obyek dalam penelitian ini adalah UMKM (Usaha Mikro Kecil dan Menengah) yang terdapat di Kota Depok. Dari 30 UMKM yang disurvey, 6 UMKM menolak melakukan wawancara dan kuesioner, 3 UMKM datanya tidak valid sehingga 21 UMKM yang memenuhi kriteria akan diteliti secara lebih lanjut. Sebagian besar UMKM Kota Depok didominasi oleh usaha kecil (64.71\%). Usaha kecil tersebut sebagian besar dikelola sendiri $(84,3 \%)$ dengan latar belakang pendidikan pengelola sebagian besar merupakan lulusan tingkat Sekolah Menengah Atas (37\%).

Tabel 1.1 Target dan Realisasi Penerimaan Pajak (Rp. Juta)

\begin{tabular}{ccccc}
\hline Tahun & Target & Realisasi & Pencapaian & Petumbuhan \\
\hline 2012 & 473.048 & 432.334 & $91,39 \%$ & $17,65 \%$ \\
2013 & 545.207 & 511.680 & $93,85 \%$ & $15,51 \%$ \\
2014 & 580.766 & 447.273 & $77,01 \%$ & $-12,59 \%$ \\
2015 & 621.452 & 598.783 & $75,65 \%$ & $-10,78 \%$ \\
\hline
\end{tabular}

Sumber : KPP Pajak Kota Depok

Berdasarkan data tabel di atas dapat dilihat bahwa pada tabel 1.1 target penerimaan pajak dari tahun ke tahun selalu meningkat tetapi tidak diikuti dengan realisasi penerimaan pajak yang berfluktuatif, dibuktikan dengan target penerimaan pajak yang mengalami peningkatan ditahun 2014 sebesar 6.52 persen dari tahun sebelumnya, akan tetapi realisasi penerimaan pajak justru mengalami penurunan ditahun 2014 sebesar 12.59 persen. Begitu pula untuk tahun 2015 terjadi penurunan realisasi penerimaan paak sebesar $10,78 \%$ dari tahun sebelumnya.

Tabel 1.2 Penerimaan Pajak Secara Umum dan Penerimaan PP 46 Kota Depok

\begin{tabular}{ccc}
\hline Tahun & Penerimaan Umum & Penerimaan PP 46 \\
\hline 2012 & 205.480 .736 .768 & 29.887 .781 .116 \\
2013 & 244.242 .301 .231 & 42.305 .504 .633 \\
2014 & 238.377 .265 .511 & 53.744 .211 .620 \\
2015 & 226.987 .667 .954 & 60.887 .934 .887 \\
\hline
\end{tabular}

Sumber ; KPP Pajak Kota Depok

Selanjutnya pada tabel 1.2 dapat dilihat bahwa sebelum penerapan PP 46/2013 terjadi peningkatan penerimaan hampir mencapai setengah dari penerimaan sebelumnya. Peningkatan tersebut tidak hanya terjadi sebelum penerapan PP 46/2013 namun juga terjadi selama dan setelah penerapan PP 46/2013 hal ini dikarenakan adanya kontrol dan sosialisasi terkait dengan PP 46/2013 walaupun penerimaan pajak secara umumnya mengalami fluktuasi. Peningkatan PP 46/2013 ini mendorong peningkatan jumlah wajib pajak serta jumlah pajak PP 46/2013 yang dibayarkan.

Walaupun pada sebelum dan setelah penerapan PP 46/2013 mengalami peningkatan penerimaan hal ini tidak mendorong peningkatan tersebut dikatakan efektif. Selain dari pada itu menurut data yang diperoleh hanya sedikit jumlah peningkatan wajib pajak yang terdaftar dan masih banyak wajib pajak yang belum mendaftarkan dirinya sebagai wajib pajak.

Berdasarkan hasil data survey terhadap para responden UMKM Kota Depok berikut ini adalah gambaran umum hasil penelitian terhadap sikap para UMKM terkait dengan pemberlakuan PP No 46 Tahun 2013.tingkat kepatuhan Wajib Pajak UMKM terhadap PP nomor 46 tahun 2013 adalah sebesar 54,1\%, yang masuk dalam klasifikasi Cukup Paham, dan untuk kepatuhan didapat hasil $\mathbf{6 2 , 2 2 \%}$ yang di klasifikasikan.

\section{Patuh}

Rendi Eka (6: 2014) mengemukakan bahwa telah ada penyesuaian regulasi terdahulu 
dengan PP 46/2013 yaitu dalam hal metode perhitungan dan pemberlakuan tarif pajak serta upaya pemerintah yang cukup strategis untuk meningkatkan efektivitas PP 46/2013. PP 46/2013 cukup efektif meningkatkan penerimaan PPh Final tetapi PP 46/2013 bukan merupakan penyebab tidak tercapainya target penerimaan pajak dalam APBN.

Tingkat kepatuhan pajak untuk UMKM di Kota Depok cukup tinggi dengan pencapaian presentase sebesar 62,22\%. Akan tetapi berdasarkan hasil penelitian yang dilakukan oleh Rendi Eka (5:2014) sejalan dengan temuan di lapangan bahwa PP 46/2013 cukup efektif meningkatkan penerimaan $\mathrm{PPh}$ Final tetapi PP 46/2013 bukan merupakan penyebab tidak tercapainya target penerimaan pajak dalam APBN.

Temuan hasil penelitian ini konsisten dengan temuan Atawodi dan Ojeka (2012) dalam penelitiannya pada kepatuhan pajak untuk UKM pengusaha di Nigeria Utara. Penelitian ini mengarah pada kesimpulan bahwa tarif pajak yang tinggi merupakan faktor utama yang dapat menyebabkan pengusaha UKM tidak mematuhi pajak. Dengan tarif pajak yang lebih tinggi, tentu saja, hal itu dapat mempengaruhi jumlah biaya yang harus ditanggung oleh pelaku bisnis. Kondisi ini akan lebih buruk ketika iklim bisnis tidak mendukung menghasilkan produk yang kurang kompetitif di pasar.

Selain itu, temuan penelitian ini dapat memperkuat pentingnya pendidikan dalam meningkatkan kepatuhan pajak di masyarakat. Hasil penelitian ini memperkuat temuan dari Mustopha Palil (2011) yang menyimpulkan bahwa pengetahuan pajak memiliki dampak yang signifikan terhadap kepatuhan pajak masyarakat dalam memenuhi kewajiban pajak terhadap pemerintah. Demikian pula, hasil penelitian yang dilakukan oleh Richardson (2006), juga memberikan hasil bahwa aspek budaya menjadi hal yang penting dalam pelaksanaan pajak di Hong Kong salah satu nya adalah melalui proses pendidikan pajak yang di kemas dalam sosialisasi pajak.

\section{SIMPULAN DAN SARAN}

\section{Simpulan}

Tingkat Voluntary Tax Compliance atau kepatuhan Wajib Pajak UMKM terhadap PP nomor 46 tahun 2013 adalah sebesar 54,1\%, yang masuk dalam klasifikasi Cukup Paham, dan untuk kepatuhan didapat hasil $\mathbf{6 2 , 2 2 \%}$ yang di klasifikasikan Patuh. Penelitian ini mengarah pada kesimpulan bahwa tarif pajak yang tinggi merupakan faktor utama yang dapat menyebabkan pengusaha UKM tidak mematuhi pajak

\section{Saran}

Keterbatasan penelitian ini adalah tentang keakuratan data. Karena jumlah sampel yang diambil tidak mewakili seluruh jumlah populasi UMKM yang terdapat di Kota Depok.

\section{REFERENSI}

Atawodi, Ojeka.(2012), "Factors That Affect Tax Compliance among Small and Medium Enterprises (SMEs) in North Central Nigeria", International Journal of Business and Management, Volume 7, Number 12,pp.87-96

Benjamin, W.P., (1990). Laporan Keuangan (Ikhtisar Akuntansi) Perusahaan Kecil, Dalam, Dalam Prosiding, Seminar Akuntan Nasional, Surabaya.

Engelschak, M. \& Loeprick,J, (2009). Designing/Reforming Presumptive Tax Sysem, International Finance Corporation-World Bank Group

Mustapha,Palil .(2011),'Determinants of Tax Compliance in Asia: A case of Malaysia", European Journal of Social Sciences, Volume 24, Number 1,pp.7-32

Richardson, Frederick M., Wright, C. T. (1986). Standards Overload: A Case for Accountant Judgment, The CPA Journal; New York.

Suhairi dan Wahdini (2006), Persepsi Akuntan Terhadap Overload Standar Akuntansi Keuangan (SAK) Bagi Usaha Kecil Dan Menengah, Makalah yang disampaikan pada SNAIX-Padang

Suhairi. (2004), Personality, Accounting Knowledge, Accounting Information Usage And Performance: A Research On Entrepreneurship Of Indonesia Medium Industries, Disertasi, USM, Malaysia.

Satyo, (2005). UKM dan Kebutuhan Standar, Media Akuntansi, 43(XII), 4.

Eka, R. (2014). Analisis Efektifitas Penerapan Peraturan Pemerintah Nomor 46 tahun 2013 Terhadap Kontribusi penerimaan 
Pajak UMKM dalam Anggaran dan belanja Negara (APBN).

Williams, L.K., Chen, R.C., \& Tearney, M.G., (1989). Accounting Standards: Overskill for Small Business, The National Public Accountant, June, pp 40-43.

Wishon, K., (1985). The FASB and Small Business: Improving the Dialogue, Journal of Accountancy; New York.

Richardson, G. (2006), ’The Impact of Tax Fairness Dimensions on Tax Compliance Behavior in an Asian Jurisdiction : The Case of Hongkong", The International Tax Journal,downloadedfromhttp://business.hi ghbeam.com.at October,20, 2013 